\title{
Recovery from Carcinomatous Meningitis by Erlotinib
}

\author{
Gen Ohara $^{\mathrm{a}}$ Katsunori Kagohashi $^{\mathrm{a}}$ Koichi Kurishima $^{\mathrm{a}}$ \\ Mio Kawaguchi ${ }^{\mathrm{a}}$ Hidetsugu Nakayama $^{\mathrm{b}}$ Hiroaki Satoh $^{\mathrm{a}}$ \\ aDivision of Respiratory Medicine, Mito Medical Center, University of Tsukuba, Mito, \\ ${ }^{b}$ Department of Radiology, Tokyo Medical University, Japan
}

\section{Keywords}

Meningitis · Erlotinib · EGFR-TKI

A 66-year-old woman presented with a 1-month history of gradually increasing cough. On admission, physical examination was unremarkable. The serum level of carcinoembryonic antigen was elevated to $156.7 \mathrm{ng} / \mathrm{ml}$ (normal: $<5.0 \mathrm{ng} / \mathrm{ml}$ ). The chest computed tomography (CT) scan demonstrated a $3.5 \times 2.5 \mathrm{~cm}$ left lung mass with several pulmonary nodules up to $1 \mathrm{~cm}$ in diameter in both lungs. Examination of a transbronchial biopsy revealed the tumor to be lung adenocarcinoma, having an in-frame deletion between codons 745 and 750 on exon 19 of the epidermal growth factor receptor (EGFR) gene. The diagnosis of clinical T2bN2M1a stage IV was confirmed. As the patient did not desire hospitalization any more, she received outpatient chemotherapy using modified doses of amrubicin. She received 7 courses of the chemotherapy, and the response was evaluated as partial response. She was in good condition for 8 months since the initiation of chemotherapy, but then she developed headache, nausea, and gait disturbance. Magnetic resonance imaging (MRI) of the head showed multiple brain metastases, with an intensive signal of the leptomeninges. As second-line therapy, the patient received $150 \mathrm{mg} /$ day erlotinib therapy. Within 2 weeks, all her symptoms dramatically disappeared. A grade 1 (National Cancer Institute common toxicity criteria (NCI-CTC) version 2.0) skin rash was observed, but was tolerable. A follow-up MRI 1 month later showed decreases in both the size and number of brain metastases and the disappearance of the intensive signal of the leptomeninges. On the chest CT scan, the pulmonary metastases in both lungs had disappeared. The patient is currently doing well and is now, 4 months after the initiation of erlotinib, able to work.

Carcinomatous meningitis is considered to be one of the oncology emergencies requiring immediate treatment [1].
Treatment options include whole-brain irradiation, systemic chemotherapy, and intrathecal chemotherapy such as methotrexate [2]. Despite these measures, the prognosis is poor with a median survival of 2-3 months, and focal neurologic dysfunctions do not improve in most cases [1]. The benefit of EGFR tyrosine kinase inhibitors (TKIs) in the treatment of carcinomatous meningitis in patients with nonsmall-cell lung cancer (NSCLC) has recently attracted attention, although all publications were only case reports or case series [3-10]. Erlotinib is widely used in patients with advanced NSCLC and its clinical utility is now highly evaluated [5]; there are reports observing that erlotinib was effective in carcinomatous meningitis after the failure of gefitinib treatment $[4,6]$. It is well known that the serum concentration of erlotinib is several times higher than that of gefitinib [6]. It is not likely that gefitinib, when administrated at $250 \mathrm{mg} /$ day, can achieve adequate levels in the central nervous system (CNS); therefore, higher doses of gefitinib may be necessary. Very recently, 2 research groups determined the concentrations of erlotinib in plasma and the cerebrospinal fluid (CSF) and confirmed that there was a measurable penetration of erlotinib into the CSF $[9,10]$. This observation suggests that erlotinib may be a therapeutic option for patients with carcinomatous meningitis developing during gefitinib treatment. As the patient had a rapid onset of symptoms, she received erlotinib rather than gefitinib in order to achieve adequate therapeutic concentrations within the CNS.

In summary, we report on a rare case of NSCLC-related carcinomatous meningitis successfully treated with erlotinib.

\section{Disclosure Statement}

There is no potential conflict of interest related to the article or the research described.

\section{KARGER \\ Fax +497614520714 \\ Information@Karger.de}

www.karger.com (c) 2011 S. Karger GmbH, Freiburs

0378-584X/11/0347-0394\$38.00/0

Accessible online at:

www.karger.com/onk
Hiroaki Satoh, MD

Division of Internal Medicine, Mito Medical Center

University of Tsukuba

Miya-machi 3-2-7, Mito, Ibaraki, 310-0015, Japan

Tel: +81 29-2312371, Fax -2215137

hirosato@md.tsukuba.ac.jp 
1 Wasserstrom WR, Glass JP, Posner JB: Diagnosis and treatment of leptomeningeal metastases from solid tumors: experience with 90 patients. Cancer 1982;49:759-772.

2 Strik H, Prömmel P: Diagnosis and individualized therapy of neoplastic meningitis. Expert Rev Anticancer Ther 2010;10:1137-1148.

3 Kim MK, Lee KH, Lee JK, Choi JH, Hyun MS Gefitinib is also active for carcinomatous meningitis in NSCLC. Lung Cancer 2005;50:265-269.

4 Yi HG, Kim HJ, Kim YJ, et al.: Epidermal growth factor receptor (EGFR) tyrosine kinase inhibitors (TKIs) are effective for leptomeningeal metastasis from non-small cell lung cancer patients with sensitive EGFR mutation or other predictive factors of good response for EGFR TKI. Lung Cancer 2009;65:80-84.
Langer C, Soria JC: The role of anti-epidermal growth factor receptor and anti-vascular endothelial growth factor therapies in the treatment of non-small-cell lung cancer. Clin Lung Cancer 2010;11:82-90.

6 Katayama T, Shimizu J, Suda K, Onozato R, Fukui T, Ito S, Hatooka S, Sueda T, Hida T, Yatabe Y, Mitsudomi T: Efficacy of erlotinib for brain and leptomeningeal metastases in patients with lung adenocarcinoma who showed initial good response to gefitinib. J Thorac Oncol 2009;4:14151419.

7 Ruppert AM, Beau-Faller M, Neuville A, Guerin E, Voegeli AC, Mennecier B, Legrain M, Molard A, Jeung MY, Gaub MP, Oudet P, Quoix E: EGFR-TKI and lung adenocarcinoma with CNS relapse: interest of molecular follow-up. Eur Respir J 2009;33:436-440.
8 Dhruva N, Socinski MA: Carcinomatous meningitis in non-small-cell lung cancer: response to highdose erlotinib. J Clin Oncol 2009;27:e31-e32.

$\checkmark$ Togashi Y, Masago K, Fukudo M, Terada T, Fujita S, Irisa K, Sakamori Y, Kim YH, Mio T, Inui K, Mishima M: Cerebrospinal fluid concentration of erlotinib and its active metabolite OSI-420 in patients with central nervous system metastases of non-small cell lung cancer. J Thorac Oncol 2010; 5:950-955.

0 Masuda T, Hattori N, Hamada A, Iwamoto H, Ohshimo S, Kanehara M, Ishikawa N, Fujitaka K, Haruta Y, Murai H, Kohno N: Erlotinib efficacy and cerebrospinal fluid concentration in patients with lung adenocarcinoma developing leptomeningeal metastases during gefitinib therapy. Cancer Chemother Pharmacol 2011;67:1465-1469. 